\title{
Extent of Knowledge and Adoption of Rice Varieties Developed by DBSKKV, Dapoli
}

\author{
Prajakta Telange $^{1 *}$, P.A. Sawant ${ }^{2}$ and Roshan Kondhavale ${ }^{3}$ \\ ${ }^{1}$ Department of Extension Education, Dr. PDKV, Akola, 444104, India \\ ${ }^{2}$ Department of Extension Education, Dr. BSKKV, Dapoli, 415712, India \\ ${ }^{3}$ Environment Management, FRI, Deemed University, Dehradun, 248195, India \\ *Corresponding author
}

\section{A B S T R A C T}

\section{Keywords}

Rice, Konkan, Adoption, Knowledge, Varieties

Article Info

Accepted:

24 June 2018

Available Online:

10 July 2018
Rice is fundamental component of farming systems and diets in many nations including India. Rice culture system is not a purely technical decision and different factors may affect it. These factors are directly related to knowledge of framers. Considering This factor, present study was conducted in three tahsils of Raigad district of Konkan region having sample size 135 rice growers with objective to study the Extent of knowledge and adoption of rice varieties developed by DBSKKV, Dapoli. This study revealed that Majority ( 88.88 per cent) of the farmers had knowledge about rice variety 'Karjat 7' developed by DBSKKV, Dapoli followed by 'Karjat 3' (70.38 per cent). However, none of the farmers had knowledge about 'Palghar' and 'Palghar 2'. Among the hybrid rice varieties developed by DBSKKV, Dapoli the farmers had knowledge about 'Sahyadri 4' (43.70 per cent) More than half (54.82 per cent) of the respondents had 'medium' adoption of the rice varieties developed by DBSKKV. The average adoption score of the respondents was 4.2. It was observed that majority (62.96 per cent) of the farmers adopted 'Karjat 7'. The average area brought under rice varieties developed by DBSKKV by the respondents was 56.93 per cent.

\section{Introduction}

India is an important centre of rice cultivation. The rice is cultivated on the largest areas in India. In India, rice is the only promising crop to acquire self sufficiency of food grain production for the population. Rice crop occupy the largest cultivated land in the country. In Maharashtra State, rice is the main crop grown in the costal districts of the Konkan region mainly in the four districts namely Thane, Raigad, Ratnagiri and Sindhudurg district. The area of Maharashtra state 1.49 million hectares with an annual production of nearly 3.27 million tones. The average productivity of the state is $1.76 \mathrm{t} / \mathrm{ha}$. Maharashtra ranks $13^{\text {th }}$ place in rice production in the country (Raigad District Socio-economic Report, 2011). Konkan region of Maharashtra state is known for its bounteous nature, beautiful landscape and variety of fruits, especially Alphanso mango. 
The major food of the people in this region is rice. It occupies an area of about 0.44 million hectares with annual production of nearly 15.10 lakh tones.

The progress and prosperity of a nation to a very great extent depends on how far its agriculture sector is advanced and modernized. Adoption of improved and up to date agricultural technologies by the majority of agriculturists is a pre-requisite to agricultural development in the developing countries, like India where the economy is mainly based on agricultural sector. After the establishment of Dr. Balasaheb Sawant Konkan Krishi Vidyapeeth, Dapoli (DBSKKV), breeding programs were guided by modern plant type concept and resulted in the development of several rice varieties with high yield potential and other desirable traits. The research for evolving the high yielding varieties of rice is being carried out at the Regional Agricultural Research Station at Karjat (Raigad), Kharland Research Station at Panvel (Raigad), Agriculture Research Station Palghar (Thane), Phondaghat (Sindhudurg), Shirgaon (Ratnagiri) and College of Agriculture, Dapoli (Ratnagiri). Dr. Balasaheb Sawant Konkan Krishi Vidyapeeth, Dapoli has developed many location specific technologies and released several note worthy varieties especially in case of rice which is the primary crop in Konkan region. University has developed 19 best varieties through selection and in modern era of rice research, developed 24 high yielding varieties with improved architecture and five excellent rice hybrids of various durations.

Therefore to assess the knowledge level of farmers regarding recommended rice varieties, the study objective entitled "Study on Extent of knowledge and adoption of rice varieties developed by DBSKKV, Dapoli." The present investigation mainly pertains to study the knowledge and adoption of high yielding varieties of rice.

\section{Need of the study}

Rice scientists, extension agents as well as planners for various reasons need to know about existing rice varieties with their percentage share in area and their respective yields. Identifying the most popular rice varieties is particularly important for rice breeders who are trying to develop new varieties with higher yield and varieties suitable for unfavorable areas/climatic conditions. It is also important to know the diffusion process of modern varieties, identifying the traits for the popularity of some varieties and investigating the reasons for the discontinuation of growing some popular varieties as well as reasons for nonadoption of these varieties.

\section{Materials and Methods}

The study was conducted in Raigad district of the Konkan region. Among the four districts of Konkan region, Raigad district ranks second in rice production, but the productivity of rice per hectare is highest in Raigad district, So it was purposively selected for this study. Raigad district comprises of fifteen tahsils. From these tahsils, three tahsils namely Karjat, Mangoan and Alibag having maximum area under rice cultivation were selected. From each tahsil, three villages having maximum area under rice cultivation were selected. Thus the total numbers of selected villages were nine. From each selected village with random sampling method 15 respondents were selected. Thus, the total sample comprises of 135 respondents. Data were collected by personally interviewing with the help of presented and well structured interview schedule and analyzed by using statistic tools like mean, standard deviation, percent frequency and correlation coefficient. In the study an ex-post facto research design of social research was used. 


\section{Results and Discussion}

The information regarding the knowledge and adoption of rice varieties developed by DBSKKV among the respondents is presented hereunder.

Variety wise knowledge of the farmers about the rice varieties developed by DBSKKV, Dapoli

The data regarding the variety wise knowledge of the farmers about the rice varieties developed by DBSKKV, Dapoli were collected and presented in Table 1.

It was observed from Table 1 that majority (88.88 per cent) of the farmers had knowledge about rice variety 'Karjat 7' developed by DBSKKV, Dapoli followed by 'Karjat 3' (70.38 per cent), 'Karjat 5' (56.29 per cent), 'Karjat 2' (50.37 per cent) and 'Ratnagiri 5' (47.41 per cent). However, none of the farmers had knowledge about 'Phondaghat 1', 'Palghar 1', 'Palghar 2' and 'Panvel 3'. Among the hybrid rice varieties developed by DBSKKV, Dapoli the farmers had more knowledge about 'Sahyadri 4' (43.70 per cent) and 'Sahyadri 2' (40.00 per cent).

The findings lead to conclude that the farmers had knowledge about very few varieties of rice developed by the DBSKKV, Dapoli. This might be because of no demonstration/minikit trials might have conducted in the study area. Another reason might be non availability of seed material in the study area. Secondly, farmers might have recommended those varieties which might used and seen in nearly area.

Overall knowledge about rice varieties developed by DBSKKV, Dapoli

An attempt was made in the present study to assess the knowledge and adoption of rice varieties developed by the DBSKKV, Dapoli of the respondents. The data regarding the knowledge level of the respondents about improved rice varieties developed by DBSKKV, Dapoli are presented in Table 2.

It is seen from Table 2 that maximum number (56.30 per cent) of the respondents had 'medium' knowledge of the rice varieties developed by the DBSKKV. More than onefourth (25.93 per cent) of the respondents had 'low' level of knowledge and 14.82 per cent of the respondents had the 'high' level of the knowledge. Only 02.95 per cent of the respondents had 'no' knowledge of the rice varieties developed by DBSKKV, Dapoli. The maximum knowledge score obtained by the farmer was 108 and average knowledge score of the farmer was 20.41

It means that majority of the respondent did not have complete knowledge regarding the rice varieties developed by DBSKKV, Dapoli. This might have happened because most of them had undertaken rice cultivation by availing the benefits of the different schemes of Zilha Parishad or Department of Agriculture of Maharashtra State. It seems that the farmers had cultivated rice varieties according to the availability of seed in the market

These findings are similar to the findings of, Umesh and Chukwa (2013), Singh and Yadav (2014).

Variety wise adoption of rice varieties developed by DBSKKV, Dapoli

The data pertaining to the rice varieties developed by DBSKKV adopted by the farmers are presented in Table 3. It is observed from Table 3 that majority (62.96 per cent) of the farmers adopted 'Karjat 7' variety of rice developed by DBSKKV followed by 'Karjat 3' (51.85 per cent), 
'Karjat 5' (39.25 per cent),'Karjat 8'(20.00 per cent), 'Karjat 2' (18.52 per cent) and 'Ratnagiri 5' (17.04 per cent). Among the hybrid rice varieties developed by DBSKKV, 16.30 per cent farmers adopted 'Sahyadri 4' followed by 'Sahyadri 2' (10.38 per cent) and
'Sahyadri' (07.41 per cent). None of the farmers had adopted 'Karjat 1', 'Phondaghat 1', 'Palghar 1', 'Palghar 2' 'Panvel 1' and 'Panvel 3' varieties of rice developed by DBSKKV, Dapoli.

Table.1 Distribution of the farmers according to their variety wise knowledge of the rice varieties developed by DBSKKV, Dapoli

\begin{tabular}{|c|c|c|c|}
\hline \multirow[t]{2}{*}{ SI.No. } & \multirow[t]{2}{*}{ Varieties } & \multicolumn{2}{|c|}{ Knowledge } \\
\hline & & Yes & No \\
\hline 1. & Karjat 184 & $35(25.92)$ & $100(74.08)$ \\
\hline 2. & Ratnagiri 24 & $46(34.08)$ & $89(65.92)$ \\
\hline 3 & Ratnagiri 711 & $5(3.71)$ & $130(96.29)$ \\
\hline 4 & Ratnagiri 73 & $27(20.00)$ & $108(80.00)$ \\
\hline 5 & Ratnagiri 1 & $8(5.92)$ & 127 (94.08) \\
\hline 6 & Karjat 3 & $95(70.38)$ & $40(29.62)$ \\
\hline 7 & Karjat 1 & $12(8.88)$ & $123(91.12)$ \\
\hline 8 & Phondaghat 1 & $0(0.00)$ & $135(100.00)$ \\
\hline 9 & Karjat 4 & $21(15.55)$ & $114(84.45)$ \\
\hline 10 & Karjat 7 & $120(88.88)$ & $15(11.12)$ \\
\hline 11 & Ratnagiri 5 & 64 (47.41) & $71(52.59)$ \\
\hline 12 & Palghar 1 & $0(0.00)$ & $135(100)$ \\
\hline 13 & Palghar 2 & $0(0.00)$ & $135(100)$ \\
\hline 14 & Karjat 5 & $76(56.29)$ & $59(43.71)$ \\
\hline 15 & Karjat 6 & $3(2.22)$ & $132(97.78)$ \\
\hline 16 & Ratnagiri 4 & $6(4.44)$ & $129(95.56)$ \\
\hline 17 & Ratnagiri 2 & $6(4.45)$ & $129(95.55)$ \\
\hline 18 & Karjat 2 & $68(50.37)$ & 67 (49.63) \\
\hline 19 & Ratnagiri 3 & $2(1.48)$ & $133(98.52)$ \\
\hline 20 & Karjat 8 & $57(42.23)$ & 78 (57.77) \\
\hline 21 & Panvel 1 & $2(1.48)$ & $133(98.52)$ \\
\hline 22 & Panvel 2 & $1(0.75)$ & $134(99.25)$ \\
\hline 23 & Panvel 3 & $0(0.00)$ & $135(100.00)$ \\
\hline 24 & Sahyadri & $28(20.75)$ & $107(79.25)$ \\
\hline 25 & Sahyadri 2 & $54(40.00)$ & $81(60.00)$ \\
\hline 26 & Sahyadri 3 & $5(3.71)$ & $130(96.29)$ \\
\hline 27 & Sahyadri 4 & $59(43.70)$ & $76(56.30)$ \\
\hline 28 & Sahyadri 5 & $7(5.18)$ & $128(94.82)$ \\
\hline
\end{tabular}


Table.2 Distribution of the respondents according to their overall knowledge about the rice varieties developed by the DBSKKV, Dapoli

\begin{tabular}{|c|c|c|c|}
\hline \multirow[t]{2}{*}{ SI. No. } & \multirow[t]{2}{*}{ Knowledge level (score) } & \multicolumn{2}{|c|}{ Respondents $(\mathrm{N}=135)$} \\
\hline & & Number & Percentage \\
\hline $\mathbf{1}$ & No knowledge $(0)$ & 4 & 02.95 \\
\hline 2 & Low (Up to 14$)$ & 39 & 25.93 \\
\hline 3 & Medium (14 to 27$)$ & 76 & 56.30 \\
\hline 4 & High (28 and above) & 20 & 14.82 \\
\hline \multicolumn{2}{|c|}{ Mean: 20.41 score Total } & 135 & 100 \\
\hline
\end{tabular}

Table.3 Distribution of the farmers according to the adoption of rice varieties developed by DBSKKV

\begin{tabular}{|c|c|c|c|}
\hline Sl. No. & Varieties & Adopters & Non adopters \\
\hline 1. & Karjat 184 & $1(0.75)$ & $134(99.25)$ \\
\hline 2. & Ratnagiri 24 & $4(02.96)$ & $131(97.04)$ \\
\hline 3. & Ratnagiri 711 & $5(03.71)$ & $130(96.29)$ \\
\hline 4. & Ratnagiri 73 & $1(0.75)$ & $134(99.25)$ \\
\hline 5. & Ratnagiri 1 & $1(0.75)$ & $134(99.25)$ \\
\hline 6. & Karjat 3 & $70(51.85)$ & $65(48.15)$ \\
\hline 7. & Karjat 1 & $0(0.00)$ & $135(100.00)$ \\
\hline 8. & Phondaghat 1 & $0(0.00)$ & $135(100.00)$ \\
\hline 9. & Karjat 4 & $5(03.71)$ & $130(96.29)$ \\
\hline 10. & Karjat 7 & 85 (62.96) & $50(37.04)$ \\
\hline 11. & Ratnagiri 5 & $23(17.04)$ & $112(82.96)$ \\
\hline 12. & Palghar 1 & $0(0.00)$ & $135(100.00)$ \\
\hline 13. & Palghar 2 & $0(0.00)$ & $135(100.00)$ \\
\hline 14. & Karjat 5 & $53(39.25)$ & $82(60.75)$ \\
\hline 15. & Karjat 6 & $1(0.75)$ & $134(99.25)$ \\
\hline 16. & Ratnagiri 4 & $1(0.75)$ & $134(99.25)$ \\
\hline 17. & Ratnagiri 2 & $2(01.48)$ & $133(98.52)$ \\
\hline 18. & Karjat 2 & $25(18.52)$ & $110(81.48)$ \\
\hline 19. & Ratnagiri 3 & $1(0.75)$ & $134(99.25)$ \\
\hline 20. & Karjat 8 & $27(20.00)$ & $108(80.00)$ \\
\hline 21. & Panvel 1 & $0(0.00)$ & $135(100.00)$ \\
\hline 22. & Panvel 2 & $1(0.75)$ & $134(99.25)$ \\
\hline 23. & Panvel 3 & $0(0.00)$ & $135(100.00)$ \\
\hline 24. & Sahyadri & $10(7.41)$ & $125(92.59)$ \\
\hline 25. & Sahyadri 2 & $14(10.38)$ & $121(89.62)$ \\
\hline 26. & Sahyadri 3 & $1(0.75)$ & $134(99.25)$ \\
\hline 27. & Sahyadri 4 & $22(16.30)$ & $113(83.70)$ \\
\hline 28. & Sahyadri 5 & $2(1.48)$ & $133(98.52)$ \\
\hline
\end{tabular}


Table.4 Distribution of the respondents according to their overall adoption of the rice varieties developed by DBSKKV, Dapoli

\begin{tabular}{|l|l|c|c|}
\hline \multirow{2}{*}{ SI. No. } & Adoption (score) & \multicolumn{2}{|c|}{ Respondents (N=135) } \\
\cline { 3 - 4 } & & Number & Percentage \\
\hline 1. & No adoption (0) & 15 & 11.11 \\
\hline 2. & Low (Up to 2) & 26 & 19.26 \\
\hline 3. & Medium (3 to 6) & 74 & 54.82 \\
\hline 4. & High (7 and above) & 20 & 14.81 \\
\hline Mean: 4.2 & score Total $\quad \mathbf{1 3 5}$ & $\mathbf{1 0 0 . 0 0}$ \\
\hline
\end{tabular}

Table.5 Distribution of the respondents according to the percent area brought under rice varieties developed by DBSKKV, Dapoli

\begin{tabular}{|l|l|c|c|}
\hline SI. No. & $\begin{array}{l}\text { Area under rice varieties (Per } \\
\text { cent) }\end{array}$ & \multicolumn{2}{|c|}{ Respondents (N=135) } \\
\cline { 2 - 4 } & Number & Percentage \\
\hline $\mathbf{1}$ & Low (Up to 33) & 21 & 17.50 \\
\hline $\mathbf{2}$ & Medium (34 to 66) & 46 & 38.33 \\
\hline $\mathbf{3}$ & High (67 and above) & 53 & 44.17 \\
\hline Mean: $56.93 \quad$ Total & $\mathbf{1 2 0}$ & $\mathbf{1 0 0 . 0 0}$ \\
\hline
\end{tabular}

Overall adoption of rice varieties developed by DBSKK V, Dapoli

The present status of adoption of rice varieties developed by DBSKKV on the field of farmers was studied. The observations on these aspects are presented and discussed in this part. The data regarding overall adoption of rice varieties developed by DBSKKV, Dapoli are presented in Table 4.

It is noticed from Table 4 that 54.82 per cent of the respondents had 'medium' adoption of the rice varieties released by DBSKKV, Dapoli, while 19.26 per cent and 14.81 per cent of the respondents had 'low' and 'high' adoption, respectively and remaining 11.11 per cent of the respondents had not adopted any variety released by DBSKKV, Dapoli. The average adoption score of the respondents was 4.2.

It can be concluded from these findings that rice growers had medium level of adoption of the rice varieties evolved by Dr. Balasaheb Sawant
Konkan Krishi Vidyapeeth Dapoli. In other words, it can be said that there is scope to increase the adoption by way of educating and motivating the farmers along with arrangements for supply of seed in time and in required quantity of developed varieties. Secondly, it can be said that all the varieties may not suitable for the area under study.

\section{Area brought under rice varieties developed by DBSKKV, Dapoli}

Out of the total area under rice, area brought under varieties developed by DBSKKV by each farmer was calculated on per cent basis. The information in this regard is presented in Table 5.

It is observed that from Table 5 maximum number of the respondents (44.17 per cent) had brought 'high' area under rice varieties developed by DBSKKV, Less than two fifth (38.33 per cent) of the respondents had brought 'medium' area and remaining 17.50 per cent of 
the respondents had brought 'low' area under rice varieties developed by the DBSKKV, Dapoli.

The findings are similar with the findings of Sridevi and Rameshbabu (2004), Tambat (2007) however, the findings are dissimilar with the findings of Thakur (2011).

In conclusion, it was observed that Majority (88.89 per cent) of the farmers had knowledge about rice variety 'Karjat 7' developed by DBSKKV, Dapoli followed by 'Karjat 3' (70.37 per cent), 'Karjat 5' (56.30 per cent), 'Karjat 2' (50.37 per cent) and 'Ratnagiri 5' (47.41 per cent). However, none of the farmers had knowledge about 'Karjat 184', 'Phondaghat 1', 'Palghar 1', 'Palghar 2' and 'Panvel 3'. Among the hybrid rice varieties developed by DBSKKV, Dapoli the farmers had knowledge about 'Sahyadri 4' (43.70 per cent) and 'Sahyadri 2' (40.00 per cent). More than half (54.82 per cent) of the respondents had 'medium' adoption of the rice varieties developed by DBSKKV. The average adoption score of the respondents was 4.2. It was observed that majority (62.96 per cent) of the farmers adopted 'Karjat 7'. Maximum number of the respondents (44.17 per cent) had brought 'high' area under rice varieties developed by DBSKKV. The average area brought under rice varieties developed by DBSKKV by the respondents was 56.93 per cent.

It was observed that the extent of adoption of rice varieties developed by DBSKKV among the farmers was at medium level. Majority of the farmers adopted Karjat 7 variety followed by Karjat 3 and Karjat 5 variety of rice developed by DBSKKV. The study has clearly indicated that most of the varieties developed by DBSKKV were not adopted by the farmers. These observations may serve as feedback for future line of action.

\section{References}

Singh, D. P. and Yadav, S. K. (2014). Knowledge and adoption gap of tribal farmers of bastar towards rice production technology. American International Journal of Research in Humanities, Arts and Social Sciences, 5(1): 54-56.

Sridevi, K and Rameshbabu, C. H. (2004). Knowledge and adoption of farmers of recommended cultivation practices for paddy. Journal of Extension Education, 15(4):3684-3687.

Tambat, R. G. (2007). A study on knowledge and adoption of recommended cultivation practices by the summer rice growers. M.Sc. (Agri.) Thesis, Dr. Balasaheb Sawant Konkan Krishi Vidyapeeth, Dapoli.

Thakur, V. V. (2011). Influence of social values on adoption of the recommended rice cultivation practices. M.Sc. (Agri.) Thesis, Dr. Balasaheb Konkan Krishi Vidyapeeth, Dapoli. (M.S.).

Umesh, G. N. and Chukwa, V. A. (2013). Determinants of adoption of improved rice production technologies in Ebonyi state of Nigeria. International Journal of Food, Agriculture and Veterinary Sciences, 3(3): 126-133.

\section{How to cite this article:}

Prajakta Telange, P.A. Sawant and Roshan Kondhavale. 2018. Extent of Knowledge and Adoption of Rice Varieties Developed by DBSKKV, Dapoli. Int.J.Curr.Microbiol.App.Sci. 7(07): 31053111. doi: https://doi.org/10.20546/ijcmas.2018.707.362 